\title{
SAPUH LEGER SIFAT KELAHITAN PADA WUKU WAYANG
}

\author{
Ketut Sri Gangga Dewi \\ Pascasarjana Institut Seni Indonesia Yogyakarta \\ e-mail: ketutgangga92@gmail.com
}

Diterima : 2 Agustus 2020. Disetujui : $2 \underline{5}$ November 2020. Dipublikasikan : 1 Desember 2020

cc) (7) $\odot 202 \underline{0}$ - DESKOVI Universitas Maarif Hasyim Latif. Ini adalah artikel dengan akses

terbuka di bawah lisensi CC BY 4.0 (https://creativecommons.org/licenses/by/4.0/)

\begin{abstract}
ABSTRAK
Penciptaan karya tari Sapuh Leger merupakan pencapaian ide serta kreativitas yang di latar belakangi oleh kelahiran seseorang. Menurut masyarakat Hindu sifat baik buruknya seseorang sangat dipengaruhi oleh hari kelahiran. Kelahiran seseorang pada Wuku Wayang merupakan kelahiran yang dianggap tidak tepat, karena dapat mempengaruhi sifat dan tingkah lakunya sehingga terlihat berbeda ketika seseroang yang lahir dihari biasa. Masyarakat Hindu Bali sangat meyakini adanya mitologi kelahiran Wuku Wayang yang berhubungan dengan kelahiran Bhatara Kala. Konon katanya Bhatara Kala memiliki sifat dan watak yang tidak baik, untuk itu setiap kelahiran pada Wuku Wayang wajib diupacarai yang disebut dengan upacara Bayuh Oton Sapuh Leger.Karya ini mengungkapkan beberapa sifat anak yang dilahirkan pada Wuku Wayang menurut umat Hindu Bali. Sifat-sifat tersebut diantaranya pemarah, egois, dan selalu menolak nasetan orang tua. Selain sifar-safatnya karya sapuh Leger juga menampilkan elemen-elemen yang digunakan dalam upacara Bayuh Oton Sapuh Leger seperti membuat Banten, meminta air suci, memercikkan air suci, dan sembayang (berdoa). Penciptaan karya tari Sapuh Leger adalah sebagai cerminan diri pada anak dan orang dewasa yang beberapa tidak dapat mengendalikan amarah dan emosionalnya terhadap orang tua. Karya ini diharapkan dapat menjadi intropeksi dan menjadi kesadaran agar menjahui sifat yang kurang baik.Penari dalam karya ini berjumlah sembilan orang penari putri dengan menampilkan lima adegan yang menegaskan pada sifat anak yang lahir pada Wuku Wayang dan proses upacara pembersihan diri.
\end{abstract}

Kata kunci: bayuh oton, sapuh leger, wuku wayang

\begin{abstract}
The creation of Sapuh Leger dance works is the achievement of ideas and creativity that is based on one's birth. According to Hindu society, the merits of a person are greatly influenced by the day of birth. Someone's birth in Wuku Wayang is a birth that is considered inappropriate, because it can affect the nature and behavior of that person so that it looks different when someone is born on an ordinary day. The Balinese Hindu community strongly believes in the mythology of the birth of Wuku Wayang which is related to the birth of Bhatara Kala. It is said that Bhatara Kala has bad character, for that every birth in Wuku Wayang must be celebrated which is called the Bayuh Oton Sapuh Leger ceremony.This work reveals some of the characteristics of children born in Wuku Wayang according to Balinese Hindus. These traits include being angry, selfish, and always rejecting parents' advice. Besides that, the work of Sapuh Leger also displays elements used in the Bayuh Oton Sapuh Leger ceremony such as making Banten, asking for Tirta or holy water, sprinkling holy water, and Sembahyang (praying). The creation of Sapuh Leger dance works is a reflection of children and adults who some cannot control their anger and emotional toward their parents. This work is expected to be introspective and become awareness in order to find out the nature that is not good.The dancers in this work number nine female dancers by presenting five scenes that emphasize the nature of the child born in Wuku Wayang and the process of self-cleansing ceremony.
\end{abstract}

Keyword: bayuh oton, sapuh leger, wuku wayang

\section{PENDAHULUAN}

Bayuh Oton Sapuh Leger adalah upacara pembersihan diri yang berfungsi sebagai pembersihan secara spiritual. Upacara ini biasanya dilaksanakan pada anak yang baru berumur 7-10 tahun dengan tujuan agar pengaruh, derita dan celaka si anak dapat segera dinetralisir dan tidak terbawa sampai pada waktu 
dewasa nanti. Namun ada juga beberapa masyarakat Hindu yang melaksanakan upacara ini setelah dewasa bahkan telah memiliki keluarga. Dalam kalender Bali ada tiga puluh jenis hari kelahiran (wuku) dan setiap jenis kelahiran telah membawa kekotoran (skala) sejak lahir. Jenis wuku diantarnya: sinta, landep, wukir, kulantir, tolu, gumbreg, wariga, warigadian, julungwangi, sungsang, dungulan, kuningan, langkir, medangsia, julung, pahang, klurut, merakih, tambir, medangkungan, matal, uye, menail, prangbakat, bala, ugu, wayang, kelawu, dukut, dan watugunung.

Dari berbagai jenis upacara pembersihan diri yang paling menarik dan unik adalah Bayuh Oton Sapuh Leger pada kelahiran Wuku Wayang. Kelahiran pada Wuku Wayang adalah kelahiran yang disakralkan bagi umat Hindu Bali. Hal tersebut dilatarbelakangi adanya mitologi yang diyakini oleh Umat Hindu sampai saat ini. Mitologi tersebut adalah tentang hubungan suami istri antara Dewa Siwa dan istrinya Dewi Uma. Hubungan yang tidak diinginkan ini kemudian melahirkan anak yang diberi nama Bahtara Kala. Menurut mitologi ketidak sengajaan hubungan tersebut mengakibatkan sifat kurang baik pada Bhatara Kala.

Masyarakat Hindu bali sangat menyakini mitologi tersebut dan yakin bahwa anak yang lahir pada Wuku Wayang akan menjadi tumbal bagi Bhatara Kala. Menurut cerita tumbal yang dimaksudkan adalah adanya perjanjian antara Bhatara Kala dan Dewa Siwa sehingga mengakibatkan anak yang kelahirannya sama dengan Bhatara Kala maka akan memiliki sifat seperti Bhatara Kala dan menjadi makanannya. Hal tersebut dihindari dengan mengadakan upacara Bayuh OtonSapuh Leger Wuku Wayang yang dilaksanakan setiap enam bulan sekali.

Penjelasan yang telah dipaparkan dapat ditarik rumusan ide penciptaan pada konsep karya yaitu memvisualisasikansifat-sifat dari Bharata Kala dan rangkaian ritual upacara Bayuh Oton Sapuh Leger dengan menghadirkan eleman-elemen yang digunakan dalam upacara. Kedua ide tersebut disimbolkan dan visualisasikan sesuai dengan kreativitas penata tari.

\section{METODE PENELITIAN}

Menciptakan karya tari merupakan bentuk penuangan ide dan kreativitas seseorang. Ide-ide tersebut diwujudkan dalam bentuk karya yang dihadirkan berdasarkan konsep penciptaan karya tari. Selain ide dan kreativis dalam merancang tari juga membutuhkan kensep dasar penciptaan yang meliputi kerangka dasar pemikiran. Kerangka dasar pemikiran yang mengawali terbentuknya karya tari yang melalui pengalaman. Hal ini disebabkan karena manusia memiliki kemampuan untuk menggali pandangan dan pengalaman-pengalaman hidupnya untuk dikembangkan ke dalam sebuah karya dengan kreativitas yang dimilikinya. Manusia diciptakan dan diberikan kemampuan khusus untuk menbuat dengan memasukkan ide-ide, simbol-simbol, dan objek-objek.
Pengalaman yang menjadi ide dasar pemikiran melalui pengalaman empiris yang secara langsung telah dialami. Hal ini menjadi penemuan kerangka dasar pemikiran yang meliputi kerangka dasar tari yang seperti rangsang tari. Rangsang yang menjadi ide dalam karya tari ini adalah rangsang auditif, visual dan idesional. Kedua yaitu tema tari yang menjadi pokok pikiran atau ide seorang penata tari yang akan disampaikan kepada penonton. Tema yang digunakan dalam karya ini yaitu pembersihan diri. Pembersihan diri secara umum tidak hanya dilakukan secara fisik tetapi juga secara batin. Ketiga yaitu judul tari, judul yang digunakan dalam karya tugas akhir ini adalah Sapuh Leger. Kata Sapuh dalam Bahasa Indonesia adalah alat untuk membersihkan, dan Leger adalah kata lain dari Leger yang berarti kotor. Penggunaan judul tersebut merupakan nama dari upacara Bayuh Oton pada Wuku Wayang. Keempat yaitu tipe tari, karya tari ini menggunakan tipe dramatik yang menampilkan tokoh Bharata Kala dan orang tua. Pengembangannya gerak diambil dari motif-motif gerak yang sering dilakukan pada saat upacara Mebayuh (upacara pembersihan).

Melalui konsep dasar pemikiran dan konsep dasar tari kemudian melanjutkan untuk membentuk karya dengan konsep penciptaan tari yaitu dalam pemilihan gerak, penari, properti, musik, rias busana, tata cahaya dan pemanggungan.

\section{Gerak Tari}

Konsep gerak dalam karya ini menggunakan gerak Ngayab bawah, Ngayab atas, Raup sebagai gerak dasar yang kemudian dikembangkan sesuai kreativitas. Bentuk-bentuk gerak yang ditampilkan lebih dominan ke bentuk gerak putri tari Bali yang cenderung menggunakan konsep rampak simultan. Selain gerak dasar putri yang dikembangkan juga menggunakan gerakan yang memiliki level besar yaitu gerakan Bhatara kala yang dikembangkan dari gerak Tari Rangda dan Tari Topeng secara umum. Gerak tersebut lebih menekankan pada getaran tangan, pengembangan ruang dan ekpresi propertinya.

2. Penari

Konsep rancangan karya tari ini disajikan ke dalam bentuk koreografi kelompok. Kereografi kelompok adalah koreografi yang ditarikan lebih dari satu penari. Pada karya ini menggunakan sembilan penari putri.

\section{Properti Tari}

Karya tari ini menggunakan properti wayang, Dulang Cane, Bokor Canang Sari,Klakat, topeng, tempat Tirta, Lis, dan Sira Wista. Wayang dalam karya ini memiliki konsep sebagai simbol dari Dewa Siwa, Bhatara kala yang menceritakan mitologi tentang kelahiran anak pada Wuku Wayang.

4. Musik Tari

Pada umumnya upacara-upacara yang ada di Bali selalu menggunakan musik sebagai sarana pendukung berjalannya upacara sama dengan halnya dengan pertunjukkan tari, musik sebagai elemen penting dan mendukung. Sapuh Leger menggunakan 
alat musik berupa Gamelan diatonis, Jublag, Kendang,Ceng-Ceng Ricik, Suling, Ketuk, Kempul, Kemong, Sunggu, dan Gongyang yang dimainkan secara langsung.

\section{Rias Busana}

Konsep riasdanbusanadalam karya tari ini menggunakan rias wajah cantik seperti rias tari pada umumnya. Kostum yang digunakanyaitukain (kamen) berwarna terang yaitu kuning, merahdanputih,Kemben warna putih, hiasan kepala warna kuning emas, dan aksesoris yang digunakan berwarna kuning emas. Warna-warna tersebut dipilih karena memiliki arti. Warnakuningyang melambangkan keagungan, warna putihmelambangkan kesucian, warnamerah melambangkankemarahan.

\section{Tata Cahaya}

Tata cahaya dalam seni pertunjukkan adalah hal yang sangat mendukung karena mampu menciptakan suasana serta mampu Membentot perhatian penonton terhadap pertunjukkannya.

\section{Pemanggungan}

Konsep karya tari ini menggunakan tata panggung yang sebenarnya digunakan dalam pementasan wayang yaitu menggunakan layar yang berwarna putih (Kelir) dan dekorasidengan gambar Boma yang berwarna ungu, coklat dan kuning emas agar warna dekorasi lebih gelap dengan warna kostum yang digunakan oleh penari. Konsep tempat yang digunakan dalam pementasan karya Sapuh Leger di Proscenium Stage, agar penonton dapat melihat garapan karya tari dengan satu arah.

\section{HASIL DAN PEMBAHASAN}

Karya ini berjudul Sapuh Leger. Sapuh Leger berasal dari dua kata Yaitu Sapuh dan Leger. Sapuh artinya meyapu atau membersihkan dan leger artinya kekotoran dibawa sejak lahir (niskala). tujuan dari terciptanya karya ini untuk memberikan cermin dan intropeksi diri bagi anak-anak atau seseorang bersifat kurang baik seperti pemarah, pemberontak dan melawan orang tua. Dalam pertunjukkannya juga menghadirkan elemen-elemen upacaranya, agar anak atau seseorang yang lahir pada hari Wuku Wayang dapat dinetralisir keburukannya. Sapuh Leger bertipe tari dramatik yang menampilkan tokoh seperti Bethara Kala dan Pemangku(pemimpin upacara keagamaan). Terdapat enam adegan pada Sapuh Leger diantaranya introduksi, bagian satu, dua, tiga, empat, dan lima.

\section{Introduksi}

Introduksi yang diawali degan cerita pertunjukkan wayang Sapuh Leger yang menceritakan tetang mitologi kelahiran anak pada WukuWayang. Adegan ini banyak berfokus pada pertunjukkan wayangnya, cerita yang dimunculkan hanya cuplikan dari cerita Bhatara Kalakemudian disajikan dengan dialog berbahasaKawi. Penyajian introduksi dalam adegan wayang diiringi oleh gerak yang menggunakan properti Kayon dengan ukuran tinggi $130 \mathrm{~cm}$ dan lebar
$58 \mathrm{~cm}$. Properti Kayon adalah bentuk imajinasi yang dihadirkan dalam ukuran yang tidak sama dengan Kayon pada umumnya. Kayon tidak dimainkan oleh dalang namun, ditarikan oleh penari dengan gerak sederhana, mengalir dan rampak.

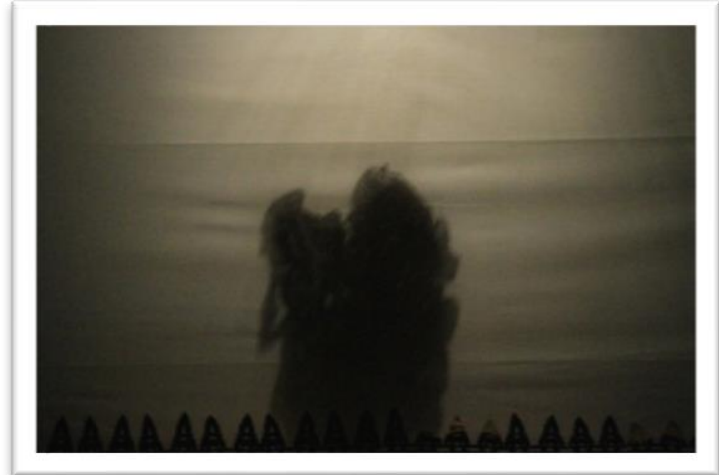

Gambar 1. Indroduksi kayon wayang Dewa Siwa dan Bhatara Kala(dok. Fanny Ramos, 2014)

\section{Adegan Pertama}

Adegan pertama yaitu menggungkapkan sebuah kegiatan yang wajib dilakukan oleh para wanita Hindu Bali pada umumnya yaitu membuat Banten. Banten adalah bentuk elemen berupa Canang, bunga dan buah yang merupakan sarana dari upacara Bayuh Oton Sapuh Leger. Kegiatan ini sebagai interpretasi dari mempersiapkan uapacara Bayuh Oton Sapuh Leger Wuku Wayang.Adegan pertama yang digerakkan oleh tigapenari putri dengan menggunakan properti Canang.Gerak yang digunakan pada adegan pertama yang mengembangkan gerak dari Nues, Mejejaitan dan Metanding.

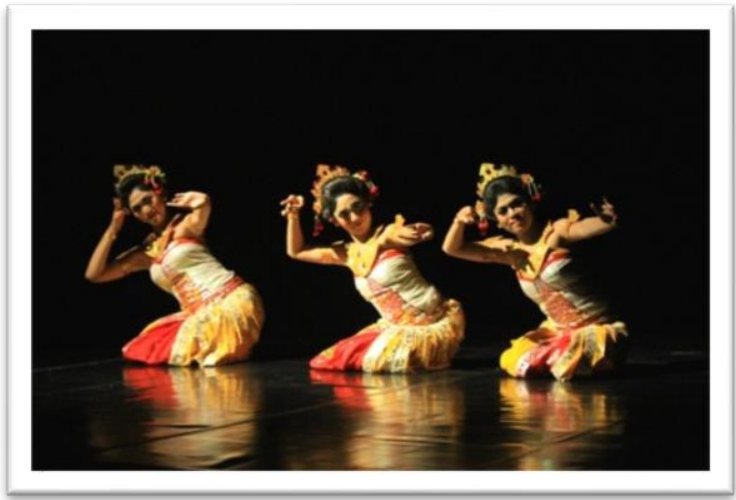

Gambar 2. Tiga penari saat bergerak dengan motif nues (dok. Fanny Ramos, 2014)

\section{Adegan Kedua}

Adegan kedua yaitu pengambaran tentang para wanita yang telah siap untuk menghaturkan Banten ke hadapan Ida Sang Hyang Widhi Wasa agar pembersihan diri berjalan dengan lancar. Jumlah penari dalam adegan kedua yaitu Sembilan penari dengan 
membawa properti DulangCane, Bokor Canang Sari dan Klakat.Dulang Cane adalah properti yang berbentuk melingkar memiliki kaki pada bagian bawah lingkarannya. Kemudian di atas lingkaran Dulang Cane terdapat hiasan dari imitasi bunga. Penggunaan properti Dulang Cane dalam adegan kedua yaitu memberikan makna Banten yang akan dihaturkan kehadapan Ida Sang Hyang Widhi Wasa karena, memiliki bentuk yang lebih tinggi dibandingkan properti yang lainnya. Kedua yaitu Bokor Canang Sariyaitu sebagai Banten yang ditujukan untuk anak atau seseorang yang dibersihkan. Ketiga yaitu Klakat adalah properti yang terbuat dari bahan bambu. Bambu tersebut dibelah-belah kemudian dirakit hingga membentuk persegi empat kemudian dihias dengandaun kelapa (janur). Makna dalam properti ini adalah sebuah Banten yang dihaturkan untuk memberikan penghormatan kepada suluh sesuatu yang tidak dapat dilihat oleh kasat mata (Bhuta Kala).

Adegan kedua ini berfokos pada penggambaran para wanita yang berama-ramai untuk menghaturkan Banten. Penari lebih banyak bergerak dengan rampak simultan. Pola lantai dalam adegan ini banyak menggunakan pola berpindah, melingkar dan asimetris. Suasana yang dimunculkan pada adegan ini yaitu ramai degan hati yang bersuka cita.

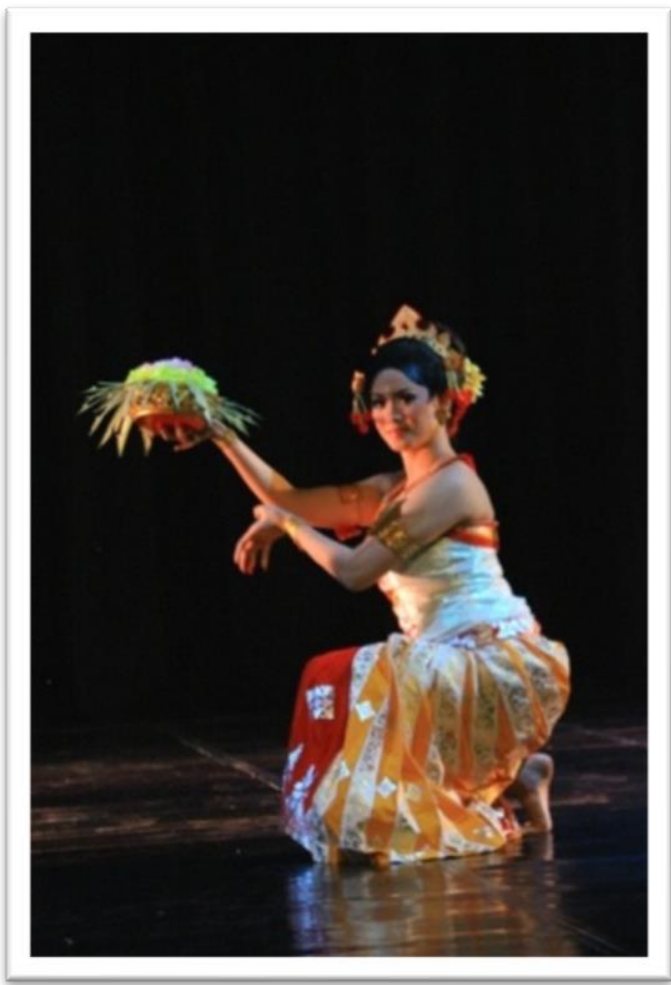

Gambar 3. Salah satu penari bergerak dengan properti Bokor Canang Sari (dok. Fanny Ramos, 2014)

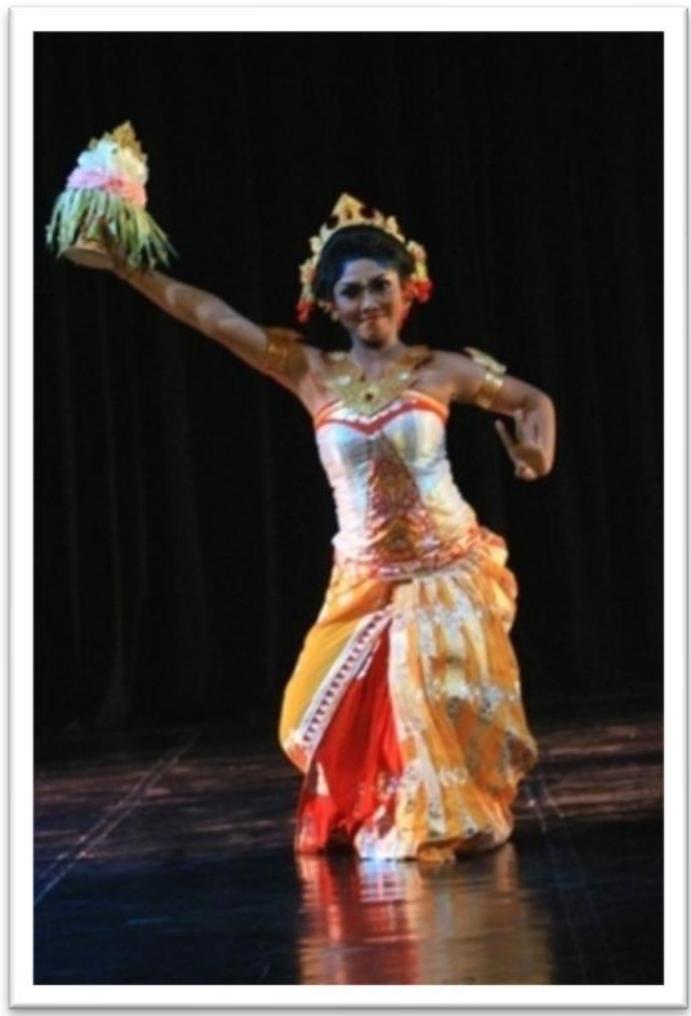

Gambar 4. Penari bergerak dengan menggunakan properti Dulang Cane (dok. Fanny Ramos, 2014)

\section{Adegan Ketiga}

Setalah selesai menghaturkan Banten maka adegan selanjutnya adalah upacara pemberihannya. Adegan ketiga ini menghadirkan tokoh Mangku Dalang dan tokoh Bhatara Kala dengan interpretasi, imajinasi dan kreativitas penata. Munculnya tokoh dalam adegan ini yaitu menyimbolkan orang tua dan sifat anak yang kurang baik ketika dilahir pada $W u k u$ wayang. Tokoh seorang Mangku Dalang sebagai orang tua yang hendak membersihkan anaknya. pada adeganMangku Dalang tidak bergerak secara koroegrafi tetapi dimunculkan dengan naturalkarena mengahadirkan suasana yang sakral saat upacara pembersihan. Tokoh Bhatara Kala sendiri sabagai anak yang akan di Bayuh Oton Sapuh Leger Wuku Wayang. Tokoh tersebut mengadirkan tiga penari yang pada awalnya memiliki paras cantik tetapi setelah akan dibersihkan penari menolak. Kerena tidak ingin bersihkan makan disimbokan dengan anak yang marah, memberontak dan melawan. Ketiga sifat ini digambarkan dengan penari yang menggunakan topeng yang berwarna merah, coklat, dan hitam. Gerak yang dimunculkan dalam sifat anak lebih pada gerak yang dengan pengembangan pengembangan ruang, level, dan waktu yang besar. Selain gerak hal pendukung lainnya yaitu pada ekspresi wajah dengan menggunakan topeng sebagai beberapa makna sifat anak yang lahir pada Wuku Wayang.

Adegan ketiga adalah puncak dari konsep karya Sapuh Leger karena memunculkan konfik pada orang tua dan anak. Konflik yang dimuncukan berupa 
Perlawanan antara Mangku Dalang dan anak yang akan di Bayuh. Konflik tersebut tidak berupa peperangan tetapi lebih menekankan pada gerak yang menyimbolkan penolakan.Suasana pada adegan ini menengangkan dan ketakutan.

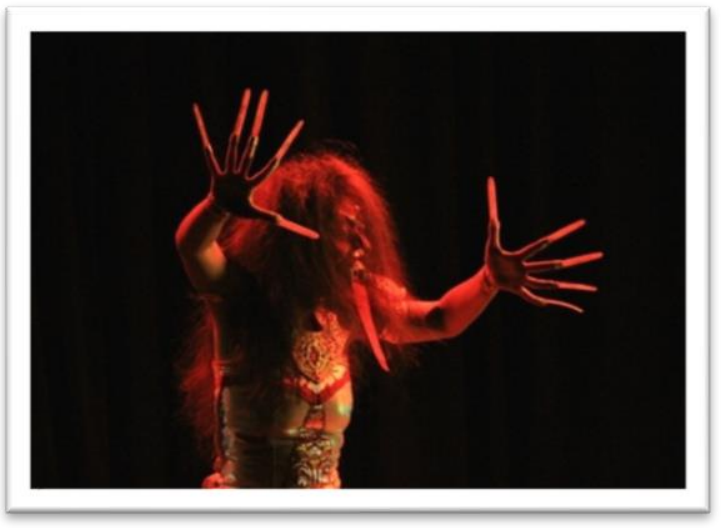

Gambar 5. visualisasi anak yang marah karena menolak untuk di Bayuh(dibersihkan) (dok. Fanny Ramos, 2014)

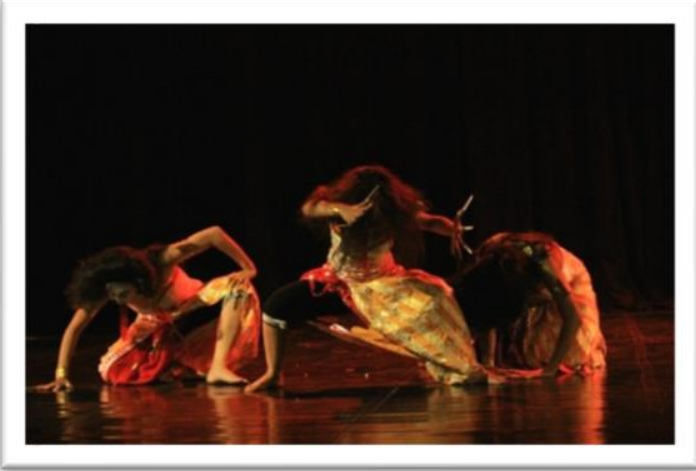

Gambar 6. Penari Bhatra Kala melepaskan topeng (sifatnya) setelah terkena Tirta dari Mangku Dalang (dok. Fanny Ramos 2014)

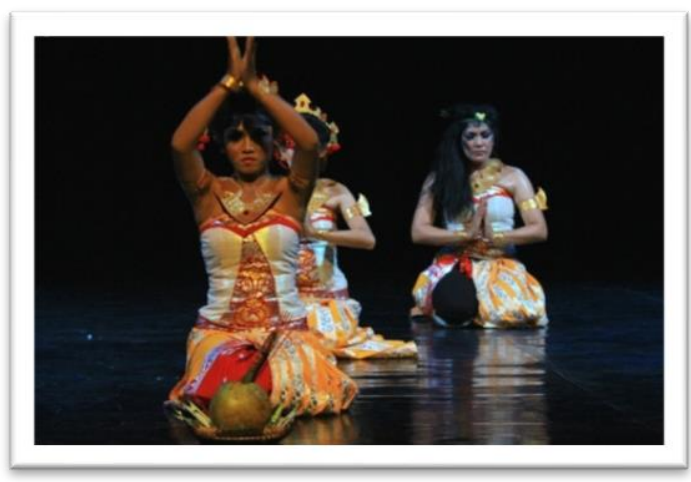

Gambar 7. Bersembahyang (berdoa) bersama (dok. Fanny Ramos, 2014)

\section{PENUTUP}

Tari adalah sebuah media ungkap yang dituangkan melalai gerak tubuh. Ungkapan yang tertuang adalah hasil dari imajinasi, kreativitas, dan pengalaman seseorang yang menciptakannya karya tersebut yaitu koroegrafer. Karya tari Sapuh Leger adalah karya yang diciptakan melalui penelitian. Namun sebuah karya tidak cukuphanya meneliti tetapi juga terlibat, mengalami, menyaksikan, dan merasakan kejadian yang hendak diungkapkan agar hal tersebut dapat merangsang panca indra.

Sapuh Leger adalah sebuah karya yang memvisualisasikan sifat anak yang lahir pada $W u k u$ Wayang. Menurut kepercayaan masyarakat Hindu Bali kelahiran ini adalah kelahiran yang tidak baik sehingga harus dibersihkan dengan upacara Bayuh Oton Sapuh Leger Wuku Wayang. Pada dasarnya sifat yang dimiliki setiap manusia adalah baik dan buruk. Dua sifat tersebut memiliki tingkatan yang sama dan tidak dapat menyalahkan bahwa hal tersebut buruk. Tetapi karya ini memberikan ilustasi bagaimana cara untuk dapat mengendalikan hal-hal negatif khusunya terhadap orang tua. Perwujudan karya ini adalah bentuk kepedulani koroegrafer bagi anak dan seseorang yang memiliki sifat kurang baik. Banyak anak atau orang dewasa yang tidak dapat mengendalikan amarah, dan egoisnya kepada orang tua. Perkataan dan perilaku orang tua memang tidak selalu benar tetapi bagiamana cara agar tetap bisa menghormatinya, meskipun tidak sependapat dengan orang tua dapat dibicarakan dengan baik.

\section{DAFTAR PUSTAKA}

Bawa Atmaja, Nengah. (2010). Ajeg Bali. LKIS Yogyakarta. Yogyakarta.

Ebdi Sanyoto, Sadjiman. Dasar-dasar Tata Rupa dan Desain. CV. Arti Bumi Intaran, Yogyakarta.

Ellfeld, Lois. (1997). Pedoman Dasar Penata Tari, Terjemahan Sal Murgianto. Lembaga Pendidikan Yogyakarta.

Hadi, Y. Sumandiyo. (1996). Aspek-Aspek Dasar Koreografi Kelompok. Manthili, Yogyakarta.

Hadi, Y. Sumandiyo. (2007). Sosiologi Tari. Pustaka, Yogyakarta.

Hawkins, Alma M. (1990). Mencipta Lewat Tari, terjemahan : Y. Sumandiyo Hadi, ISI Yogyakarta, Yogyakarta.

Humprey, Doris. (1959). The Art of Making Dance. Random House, Inc, New York

Martono, Hendro. (2008). Sekelumit Ruang Pentas. Cipta Media, Yogyakarta.

Martono, Hendro. (2010). Mengenal Tata Cahaya Seni Pertunjukan. Cipta Media, Yogyakarta.

Martono, Hendro. (2012). Ruang Pertunjukan dan Berkesenian. Cipta Media, Yogyakarta.

Meri, La. (1987). Komposisi Tari Elemen-elemen Dasar, terjemahan Soedarsono. ISI Yogyakarta, Yogyakarta.

Mider Adnyana, I Nyoman. (2012). Arti dan Fungsi Banten. Pustaka Bali Post, Denpasar.

Pasek Swastika, I Ketut. (2013). Bayuh Bayah Dayuh, Pawetuan. CV. Kayumas Agung, Denpasar. 
Putu Surayin, Ida Ayu. (2012). Manusia Yasna. Paramita Surabaya, Surabaya.

Singgih Wikarman, I Nyoman. (1998). Bayuh Oton. Paramita Surabaya, Surabaya.

Smith, Jacquiline, M. (1985), Komposisi Tari, Sebuah Petunjuk Praktis Bagi Guru, terjemahan : Ben Suharto. Yogyakarta: Ikalasti.

Wicaksana, I Dewa Ketut. (2007). Wayang Sapuh Leger. Pustaka Bali Post, Denpasar.
Yadnya, Manuaba, I Gede Suyata. (2013). Bayuh Oton. Pustaka Bali Post, Denpasar. 